\title{
Co-cultures with integrated in situ product removal for lactate-based propionic acid production
}

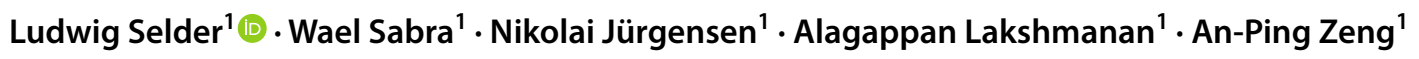

Received: 2 November 2019 / Accepted: 20 January 2020 / Published online: 13 February 2020

(c) The Author(s) 2020

\begin{abstract}
Propionic acid (PA) is a valuable organic acid for the food and feed industry, but no bioproduction at industrial scale exists so far. As product inhibition is a major burden for bioprocesses producing organic acids, in situ product removal (ISPR) is desirable. Here, we demonstrate a new strategy to produce PA with a co-culture coupled with ISPR using electrodialysis. Specifically, Bacillus coagulans first produces lactic acid (LA) from sugar(s) and LA is converted to PA using Veillonella criceti. Applying ISPR to the mentioned co-culture, the specific PA yield was increased from 0.35 to $0.39 \mathrm{~g} \mathrm{~g}^{-1}$ compared to no ISPR usage. Furthermore, the productivity was increased from 0.63 to $0.7 \mathrm{~g} \mathrm{~L}^{-1} \mathrm{~h}^{-1}$ by applying ISPR. Additionally, it was shown that co-consumption of xylose and glucose led to a higher PA productivity of $0.73 \mathrm{~g} \mathrm{~L}^{-1} \mathrm{~h}^{-1}$, although PA yield was only increased slightly up to $0.36 \mathrm{~g} \mathrm{~g}^{-1}$.
\end{abstract}

Keywords In situ product removal $\cdot$ Co-culture $\cdot$ Propionic acid $\cdot$ Electrodialysis

\section{Introduction}

Propionic acid (PA) is an important compound used in a variety of industries, e.g., for the production of food, polymers and pharmaceuticals $[1,38]$. However, up to now, the vast majority of PA is produced via petrochemical processes, namely the Reppe and Larsson process [15]. To steer the chemical industry towards sustainable production routes, biotechnological processes have been studied to produce PA from bio-based resources [16; 35]. So far, the biotechnological route cannot compete economically with the petrochemical production process, due to limited yield, productivity, and high costs of product recovery when using bio-based substrates. Limitations during fermentation for bio-based PA occur mainly due to product inhibition and the generation of side products such as acetic acid (AA) and succinic acid (SA) $[7,15,30]$. The vast majority of studies concerning microbial PA production have been conducted with bacteria of the Propionibacteria species. Several strains such as Propionibacterium acidipropionici, $P$. shermanii, and $P$.

An-Ping Zeng

aze@tuhh.de

1 Institute of Bioprocess and Biosystems Engineering, Hamburg University of Technology, 21073 Hamburg, Germany freudenreichii have been investigated and bear the potential of reliable PA producers [12, 31-33]. However, product inhibition as well as side product formation are still the major challenges to overcome to reach a desired product titer of at least $100 \mathrm{~g} \mathrm{~L}^{-1}$ making a fermentative approach economic viable $[15,26]$. Furthermore, these processes depend on glucose or glycerol as substrates and have a broad product spectrum, meaning that substrate is wasted for byproducts. A potential solution to this problem is the use of lactate as an intermediate substrate to produce PA and the application of ISPR to tackle the problem of product inhibition.

\section{Lactate as a platform substrate}

Lactate is an important building block in the chemical industry with a well-established bio-based production process. Its production can be conducted relatively cheap and with economically viable product titers, productivities, and yields. A broad range of studies have been conducted with different substrates and operation modes with the highest product titer reported at $231 \mathrm{~g} \mathrm{~L}^{-1}$ by $R$. oryzae in fed-batch mode with glucose as substrate [34]. Various chemicals can be produced starting from bio-based lactate either via chemical catalysis [11] or directly by microorganisms which are able to utilize lactate as a substrate for growth such as Veillonella spp. [4, 5, 28]. 
Bacillus coagulans is an advantageous lactate producer as it possesses a broad $\mathrm{pH}$ spectrum ranging from 5.0 to 7.0 and a temperature tolerance up to $52^{\circ} \mathrm{C}$ [37]. It is a Gram-positive and facultative anaerobe and able to grow in acidic environments generating high titers of L-lactate [14]. Of significant interest is the high selectivity which enables enantiomeric pure products. Zhang et al. [36] genetically modified a $B$. coagulans capable of producing D-lactate only, with an optical purity of $99.9 \%$. Furthermore, the obtained yield of $0.98 \mathrm{~g} \mathrm{~g}^{-1}$, product titer of $145 \mathrm{~g} \mathrm{~L}^{-1}$, and possibility of unsterile fermentation prove the economic viability. Comparable results were achieved with a different $B$. coagulans strain selectively generating $L$-lactate with a final product titer of $182 \mathrm{~g} \mathrm{~L}^{-1}$ at a yield of $0.92 \mathrm{~g} \mathrm{~g}^{-1}$ [22]. Besides the high product titers and yields, B. coagulans tolerates a broad range of substrates such as corn steep powder, Jerusalem artichoke powder, wheat straw and lignocellulosic hydrolysates [2, 6, 30, 32]. These characteristics offer the chance to avoid using expensive substrates and instead using lowcost sustainable resources.

Co-cultures or cascade cultures can be used to exploit the availability of cheap substrates by converting them into lactate first which is then transformed into value-added chemicals. Sabra et al. [27] used a co-culture of Veillonella criceti and Lactobacillus zeae to produce PA from flour hydrolysate with a final product titer of $30 \mathrm{~g} \mathrm{~L}^{-1}$. The advantage of using $V$. criceti for the PA generation is the PA productivity of $0.39 \mathrm{~g} \mathrm{~L}^{-1} \mathrm{~h}^{-1}$. Productivities reached by Propionibacterium spp. are generally lower [27]. Apart from the lower productivity, the specific growth rate of Propionibacterium acidipropionici is ceasing with the generation of $\mathrm{PA}$ and reaching values close to 0 at concentrations above $10 \mathrm{~g} \mathrm{~L}^{-1}$ [20]. As $V$. cricet $i$ is not able to use glucose or xylose but lactate as an energy source, the carbon source has to be transformed to lactate first. However, during the fermentation for PA, the concentration of lactate has to be kept below $10 \mathrm{~g} \mathrm{~L}^{-1}$ to avoid substrate inhibition and PA has to be removed as product inhibition occurs [27].

\section{In situ product removal (ISPR) by electrodialysis}

To overcome the aforementioned challenges, process intensification techniques can be applied, in this case in situ product removal (ISPR). There are several ISPR techniques suitable for the recovery of organic acids from fermentation, such as adsorption, extraction, nanofiltration/reverse osmosis, electrodialysis, and precipitation [21]. The problem arising when using filtration or adsorption methods is the fouling due to the cell attachment. In the case of precipitation, byproducts are generated in large quantities. Therefore, extraction and electrodialysis are the most common applications regarding ISPR. Extraction bears the obstacle of solvent toxicity as especially for the extraction of carboxylic acids, amine-based extractants diluted in long-chain hydrophobic organic compounds are the method of choice [17-19]. In this study, a modified electrodialysis, namely reversed electro-enhanced dialysis (REED), was used, selectively removing monovalent organic acids with an electric field as the driving force for ion migration. The REED technology has already been applied successfully as means for process intensification as it was shown that butyric acid production can be enhanced by applying REED [3]. The same setup was also studied to enhance the production of lactate [24]. In both cases, due to the REED usage and the internal membrane arrangement, operation malfunction because of fouling did not occur.

\section{Materials and methods}

\section{Microorganisms and medium}

Bacillus coagulans (DSMZ 2314) and Veillonella criceti (DSMZ 20734) were purchased from the German Collection of Microorganisms and Cell Cultures (DSMZ).

Bacillus coagulans was cultivated in a medium-containing: $13 \mathrm{~g} \mathrm{~L}^{-1}$ yeast extract, $10 \mathrm{~g} \mathrm{~L}^{-1}$ peptone, $5 \mathrm{~g} \mathrm{~L}^{-1}$ glucose, $1 \mathrm{~g} \mathrm{~L}^{-1}$ soluble starch, $5 \mathrm{~g} \mathrm{~L}^{-1}$ sodium chloride, and $3 \mathrm{~g} \mathrm{~L}^{-1}$ sodium acetate. Anaerobic conditions were ensured by flushing with pure nitrogen for $20 \mathrm{~min}$ at $80^{\circ} \mathrm{C}$. After cooling, $0.5 \mathrm{~g} \mathrm{~L}^{-1}$ cysteine- $\mathrm{HCl}$ was added.

Veillonella criceti was cultivated in a medium-containing: $2 \mathrm{~g} \mathrm{~L}^{-1}$ yeast extract, $2 \mathrm{~g} \mathrm{~L}^{-1}$ peptone, $15 \mathrm{~g} \mathrm{~L}^{-1} \mathrm{KH}_{2} \mathrm{PO}_{4}$, $5 \mathrm{~g} \mathrm{~L}^{-1} \mathrm{~K}_{2} \mathrm{HPO}_{4}$, and $10 \mathrm{~g} \mathrm{~L}^{-1}$ potassium lactate. Anaerobic conditions were ensured by flushing with pure nitrogen for $20 \mathrm{~min}$ at $80^{\circ} \mathrm{C}$. After cooling, $0.5 \mathrm{~g} \mathrm{~L}^{-1}$ cysteine$\mathrm{HCl}$ and a vitamin solution were added: $0.25 \mathrm{mg} \mathrm{L}^{-1}$ biotin, $0.01 \mathrm{mg} \mathrm{L}^{-1}$ folic acid, $2.5 \mathrm{mg} \mathrm{L}^{-1}$ Pyridoxin $\mathrm{HCl}$, $50 \mathrm{mg} \mathrm{L}^{-1}$ Thiamine $\mathrm{HCl}, 50 \mathrm{mg} \mathrm{L}^{-1}$ Riboflavin, $2.5 \mathrm{mg} \mathrm{L}^{-1}$ Nicotinic acid, $2.5 \mathrm{mg} \mathrm{L}^{-1}$ Calcium Pantothenate, and $0.05 \mathrm{mg} \mathrm{L}^{-1}$ Vitamin B12. The vitamin solution was passed through a sterile filter $(0.22 \mu \mathrm{m})$ before addition.

Co-cultures were performed with a media consisting of the following ingredients: $10 \mathrm{~g} \mathrm{~L}^{-1}$ yeast extract, $10 \mathrm{~g} \mathrm{~L}^{-1}$ peptone, $1.7 \mathrm{~g} \mathrm{~L}^{-1}\left(\mathrm{NH}_{4}\right)_{2} \mathrm{SO}_{4}, 5 \mathrm{~g} \mathrm{~L}^{-1}\left(\mathrm{NH}_{4}\right)_{2} \mathrm{PO}_{4}, 0.4 \mathrm{~g} \mathrm{~L}^{-1}$ $\mathrm{MgSO}_{4} \cdot 7 \mathrm{H}_{2} \mathrm{O}, 15 \mathrm{~g} \mathrm{~L}^{-1} \mathrm{KH}_{2} \mathrm{PO}_{4}, 5 \mathrm{~g} \mathrm{~L}^{-1} \mathrm{~K}_{2} \mathrm{HPO}_{4}$, and $1.2 \mathrm{~mL} \mathrm{~L}^{-1}$ of the vitamin solution.

The glucose and xylose used in this study was generated from wheat straw and kindly provided by Prof. Irina Smirnova, Institute of Thermal Separation Processes, Hamburg University of Technology. Xylose solution was treated with activated carbon to remove acetate and analyzed using HPLC. No acetate was found in the xylose solution after this treatment. For glucose production, wheat straw was treated via the liquid hot-water process and supplied as a liquid biomass hydrolysate [25]. 


\section{Fermentation process}

Cultivations were either performed in a stirred $2.4 \mathrm{~L}$ glass bioreactor (Bioengineering AG, Switzerland) or in a stirred $1.8 \mathrm{~L}$ glass bioreactor (DASGIP AG, Germany). The $\mathrm{pH}$ was controlled and corrected with $6 \mathrm{M} \mathrm{KOH}$. The fermentation was initiated after the addition of $10 \%(\mathrm{v} / \mathrm{v})$ inoculum from preculture. Samples were withdrawn sterile at regular intervals and the sugar concentration as well as the organic acid concentration were determined. Pre-cultures were grown in the respective medium under anaerobic conditions in glass vials with butyl rubber stoppers and aluminum clamps. Fermentations were performed at $37^{\circ} \mathrm{C}$ and a controlled $\mathrm{pH}$ of 6.2 .

Cascade cultures were performed using the fermentation broth of the B. coagulans fermentation as substrate. Prior to usage, cells were removed by centrifugation (Heraeus Megafuge) at $8500 \mathrm{rpm}$ for $15 \mathrm{~min}$.

Experiments to determine the inhibition by lactate were performed in anaerobic flasks $(50 \mathrm{~mL})$ with butyl rubber stops. Potassium lactate was added externally before inoculation.

\section{In situ product removal by electrodialysis}

The in situ product removal (ISPR) is accomplished via a modified electrodialysis unit. In this study, the REED unit is connected through a loop system with the bioreactor. In Fig. 1, it can be seen that the fermentation broth is cycled from the fermenter bottom subsequently through the electrodialysis unit and back into the fermenter at the top. In parallel, $0.3 \mathrm{M} \mathrm{NaOH}$ is pumped in the alternate flow channels of the REED stack from a reservoir in a circular fashion. The fermentation broth gets depleted of monovalent organic ions and the $\mathrm{NaOH}$ stream enriched in organic acids. The stack (PCCell, Germany) consists of ten anion-exchange (PC 100 $\mathrm{D}$, PCCell) membranes, each with an effective membrane area of $0.0064 \mathrm{~m}^{2}$. These membranes can only be penetrated by monovalent negatively charged ions. The electrodes are manufactured of $\mathrm{Pt} / \mathrm{Ir}$ enabling polarity switching. The polarity switch is enabled with a self-built device enabling switching at any time interval higher than $10 \mathrm{~s}$. A maximum of $36 \mathrm{~V}$ and $4.5 \mathrm{~A}$ can be applied. The setup was operated in constant current mode. If not specifically mentioned, the current density was set at $400 \mathrm{~A} \mathrm{~m}^{-2}$ with a reversal of the polarity each $60 \mathrm{~s}$. Electrode chamber flushing was performed with $0.25 \mathrm{M} \mathrm{Na}_{2} \mathrm{SO}_{4}$. Acids separated by the ISPR setup are gained as salts, namely $\mathrm{Na}^{+}$as the counter stream of the fermentation broth is a $0.3 \mathrm{M} \mathrm{NaOH}$ solution. Detailed description of the setup as well as the anti-fouling mechanisms can be found in Prado-Rubio et al. [24]. Sterility was ensured by cycling $70 \%(\mathrm{v} / \mathrm{v})$ ethanol for $30 \mathrm{~min}$.
Disinfection was performed by circling $70 \%$ (v/v) ethanol for $30 \mathrm{~min}$, deionized water, and 5\% (v/v) nitric acid for $30 \mathrm{~min}$.

\section{Analytical methods}

PA, AA, LA, xylose, and glucose were analyzed by HPLC (Kontron, Germany) with an Aminex HPX-87H column $(300 \times 7.8 \mathrm{~mm})$ at $60{ }^{\circ} \mathrm{C}$ and $\mathrm{UV}(210 \mathrm{~nm})$ and RI detectors. As mobile phase, $5 \mathrm{mM} \mathrm{H}_{2} \mathrm{SO}_{4}$ was used. All samples were filtered $(0.22 \mu \mathrm{m})$ before HPLC analysis. The OD of the samples was measured using a UV/VIS V 1200 Spectrometer (VWR) at $600 \mathrm{~nm}$.

\section{Results and discussion}

\section{Monoculture of B. coagulans}

Figure 2 depicts the results of glucose fermentation using B. coagulans with the addition of glucose at a fermentation time of $20 \mathrm{~h}$. Production of lactate exceeding the glucose consumption between 10 and $20 \mathrm{~h}$ of fermentation time is obviously due to use of complex medium components. The latter is necessary for cell growth, especially to provide the crucial nitrogen source [23]. The average lactate productivity peaked at $3.6 \mathrm{~g} \mathrm{~L}^{-1} \mathrm{~h}^{-1}$ during the exponential growth with a specific yield of $0.99 \mathrm{~g}$ lactate per g glucose with a final titer of $90.2 \mathrm{~g} \mathrm{~L}^{-1}$. As it can be determined from the specific yield, almost all of the substrate is converted into lactate, and only a small fraction is used for energy and biomass generation. For lactate generation, B. coagulans makes use of the pentose-phosphate pathway efficiently producing lactate without any byproducts [22]. Therefore, B. coagulans can serve as an optimal partner for lactate formation in cocultures due to its efficient transformation of the substrate.

\section{Monoculture of $V_{\text {. criceti }}$}

Fermentation of lactate using $V$. criceti reached a maximum PA titer of $11.9 \mathrm{~g} \mathrm{~L}^{-1}$ with $4.5 \mathrm{~g} \mathrm{~L}^{-1} \mathrm{AA}$ as a coproduct. The PA productivity reached $0.47 \mathrm{~g} \mathrm{~L}^{-1} \mathrm{~h}^{-1}$ with a yield of $0.49 \mathrm{~g}$ PA per $\mathrm{g}$ LA. However, it can be seen from the curve of OD development that above a PA concentration of $6.5 \mathrm{~g} \mathrm{~L}^{-1}$ growth ceases, and the OD drops, indicating lysis of cells. Several inhibition mechanisms have been proposed, though the exact mechanism of inhibition by organic acids towards microbial species remains unclear. Visible from Fig. 3 is the accompanied production of AA besides PA from lactate. According to Fuchs et al. [13], Veillonella spp. makes use of the available substrate either through the methyl-malonyl pathway generating PA via oxaloacetate or through the transformation of pyruvate to AA. Notable is the fact that Veillonella does not possess a 

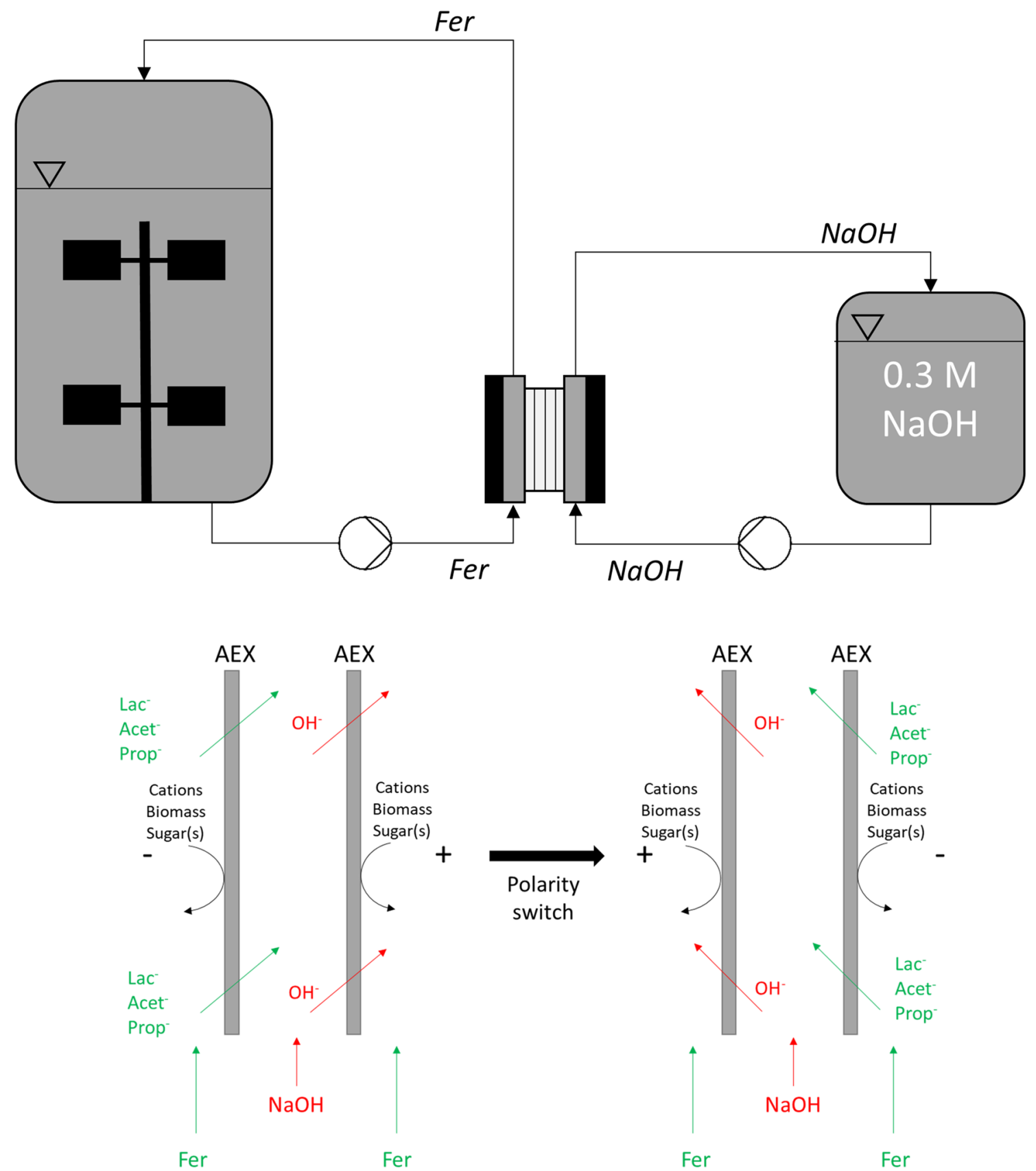

Fig. 1 REED setup with in situ connection to bioreactor; Fer: stream of fermentation broth; $\mathrm{NaOH}$ : stream of $\mathrm{NaOH}$; electrodes are flushed with electrolyte solution (not shown). Lower picture depicts the

transcarboxylase able to convert pyruvate to oxaloacetate directly, but a bypass route using a pyruvate carboxylase and a methyl-malonyl-CoA decarboxylase. The stoichiometry of the proposed pathway demands the generation of $2 \mathrm{~mol} \mathrm{PA}$ and $1 \mathrm{~mol}$ of AA from $3 \mathrm{~mol}$ of lactate. The transformation of lactate to AA is used to generate ATP and $\mathrm{NADH}$, while the PA route makes use of the generated NADH.

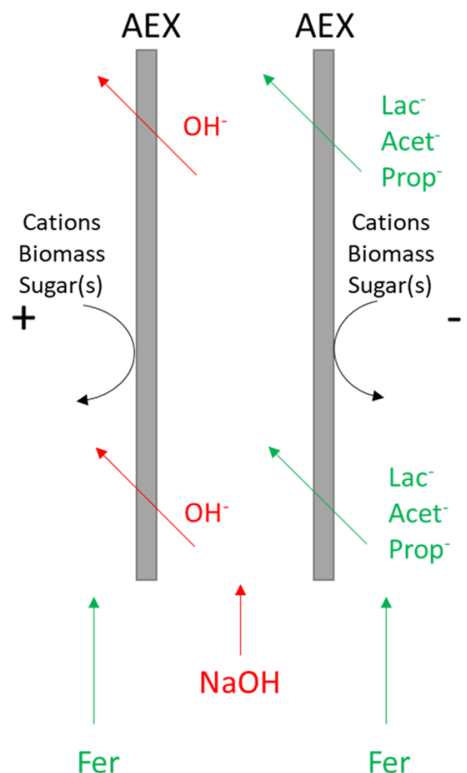

functionality of the polarity reversal which leads to a change in ion flux direction (Lac Lactate, Prop PA, Acet AA, AEX anion-exchange membrane)

\section{Co-culture of B. coagulans and V. criceti}

Co-cultures of B. coagulans and V. criceti were conducted in such a way that glucose was added in pulses to avoid overproduction of lactate diminishing the growth of $\mathrm{V}$. criceti. Therefore, only that much glucose was added that the maximum lactate concentration reachable was always below $10 \mathrm{~g} \mathrm{~L}^{-1}$. Sabra et al. were able to show that strong inhibition 


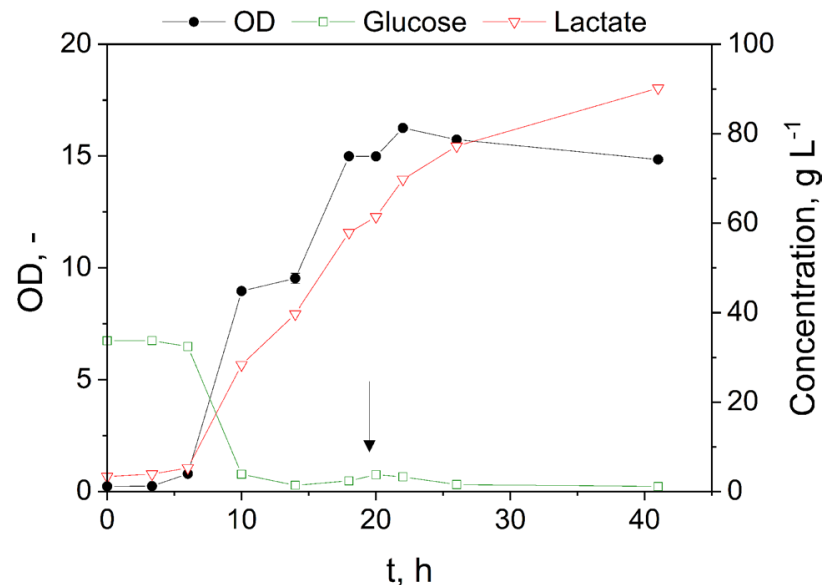

Fig. 2 Glucose fermentation using B. coagulans as monoculture. The arrow indicates the addition of glucose

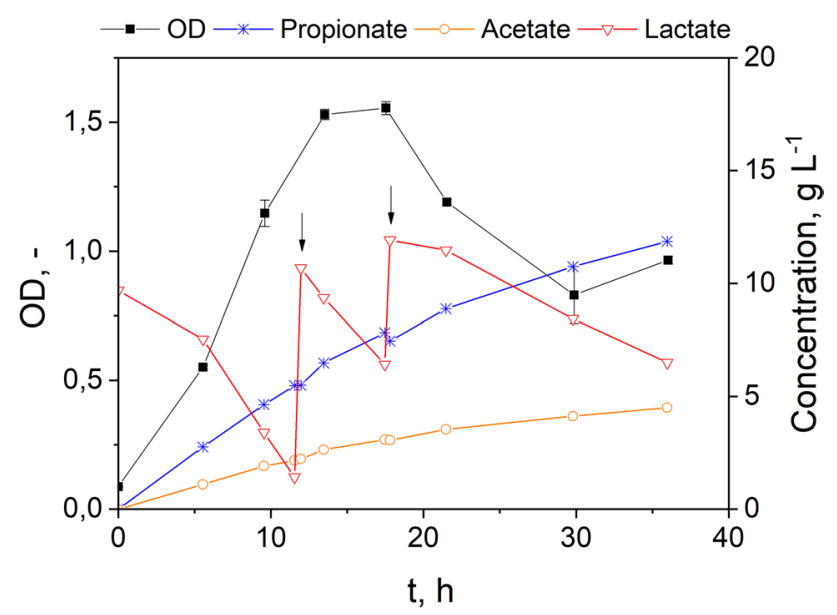

Fig. 3 Repeated batch fermentation of lactate using V. criceti. Pulses of lactate from cultivation of $B$. coagulans were added at the indicated time points (black arrow)

occurs of $V$. criceti because of PA and LA. Above a PA or LA concentration above $10 \mathrm{~g} \mathrm{~L}^{-1}$, respectively, growth ceased rapidly.

Veillonella criceti was added $13.2 \mathrm{~h}$ after the inoculation of the bioreactor with $B$. coagulans to ensure the availability of lactate as a substrate generated from $B$. coagulans after its initial lag phase.

As it can be seen from Fig. 4, the maximum product titer achieved by a co-culture was $15.4 \mathrm{~g} \mathrm{~L}^{-1}$ and $3.8 \mathrm{~g} \mathrm{~L}^{-1}$ for PA and AA, respectively. With the addition of the bacteria, glucose was added as well and almost immediately converted to lactate reaching a maximum value of $21.6 \mathrm{~g} \mathrm{~L}^{-1}$. The yield for PA from glucose is $0.35 \mathrm{~g} \mathrm{~g}^{-1}$ with a productivity of $0.63 \mathrm{~g} \mathrm{~L}^{-1} \mathrm{~h}^{-1}$. In this case, an inhibition of $V$. criceti does not seem to occur, as PA and AA are generated, although lactates exceeds the critical inhibition concentration and PA

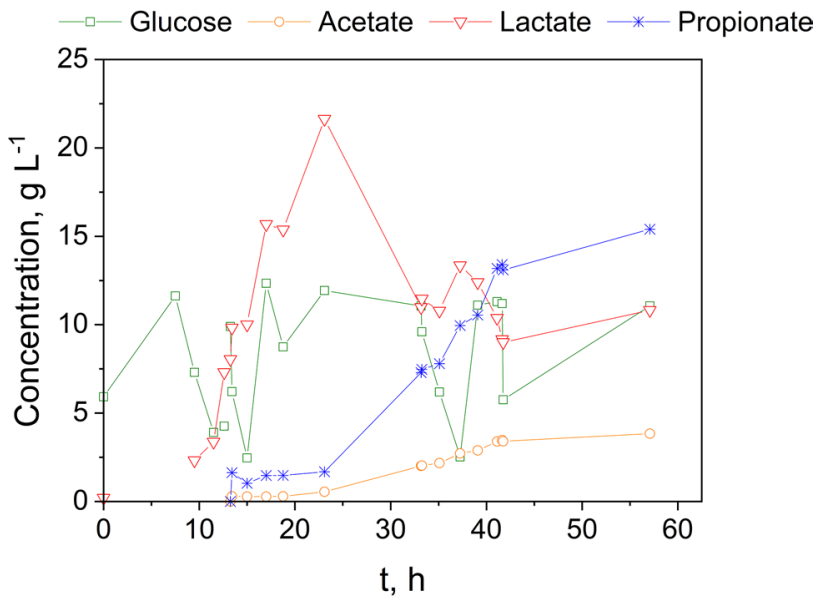

Fig. 4 Co-culture of B. coagulans and V. criceti using glucose as substrate

production is still detectable after the spike of LA at $22 \mathrm{~h}$. This leads to the conclusion that the presence of $B$. coagulans might enable a higher tolerance of $V$. criceti towards PA and can be characterized as a mutualism culture [8].

\section{Co-culture of B. coagulans and V. criceti with in situ electrodialysis}

To intensify the production process, the fermentation was coupled with an in situ REED setup as described earlier. This system enables the selective removal of monovalent ions and can theoretically allow infinite fermentation duration by continuously removing inhibiting substances accumulated inside the bioreactor. For the duration of the fermentation, glucose was added in pulses to avoid concentrations of lactate exceeding inhibitory levels. The REED setup was switched on when LA was consumed and PA and AA were generated. After the completion of an REED run, glucose was added again. Figure 5 shows the final product titer in the fermentation broth and Fig. 6 shows the final titer in the $\mathrm{NaOH}$ stream.

These results show the beneficial impact of the in situ product removal on the fermentation process. Besides an improved yield of $0.39 \mathrm{~g} \mathrm{~g}^{-1} \mathrm{PA}$, the productivity was enhanced, as well. Combining the concentrations reached in the electrodialysis, $\mathrm{NaOH}$ compartment and the fermentation $24.3 \mathrm{~g} \mathrm{~L}^{-1}$ of PA have been produced with a productivity of $0.70 \mathrm{~g} \mathrm{~L}^{-1} \mathrm{~h}^{-1}$. As it can be seen from Fig. 5, although inhibiting concentrations of PA are reached throughout the fermentation, PA is produced again after the removal of PA and AA. Figure 6 shows that the electrodialysis was applied four times totally, indicated by the increase in PA and AA in the dilute stream and the resulting depletion of these organic acids in the fermentation media. On average, the removal rate is $1.3 \mathrm{~g} \mathrm{~L}^{-1} \mathrm{~h}^{-1}$ 


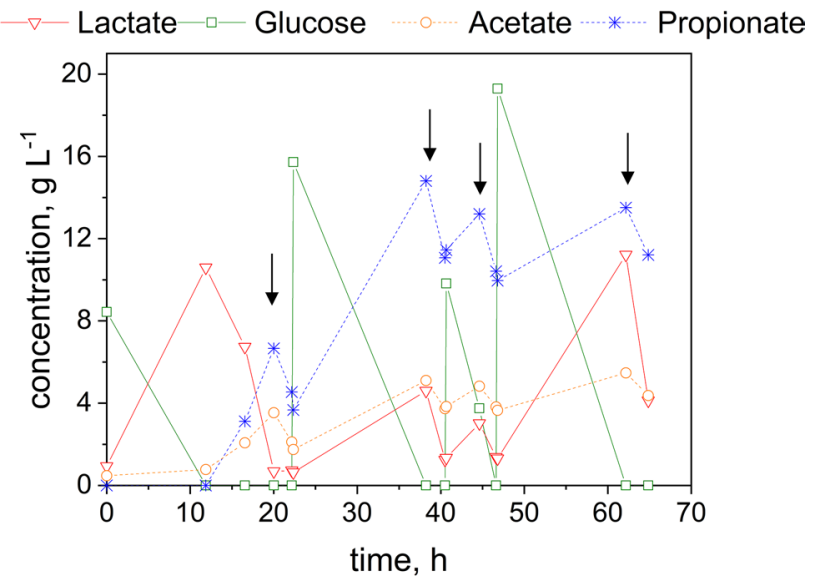

Fig. 5 Fermentation of glucose using B. coagulans and V. criceti in co-culture. Black arrows indicate the start of an ISPR cycle (run time $2 \mathrm{~h})$

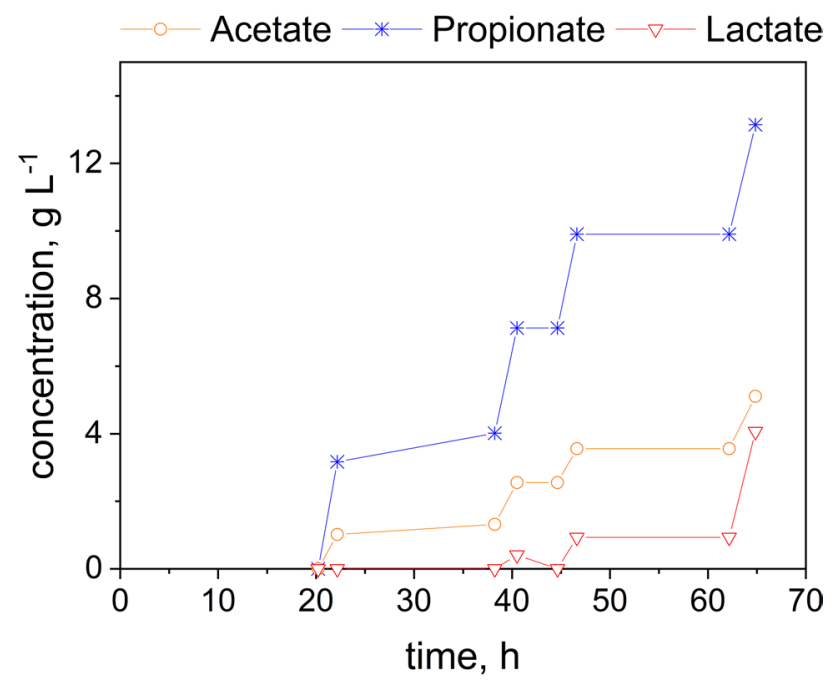

Fig. 6 In situ product removal of PA, LA, and AA from fermentation ( $\mathrm{NaOH}$ compartment)

for PA. As $V$. criceti is the bottleneck, due to its various inhibitions, in this bioprocess, close attention has to be paid to these bacteria. Therefore, the electrodialysis was only run for $2 \mathrm{~h}$. By running the electrodialysis for a longer time span, more PA and AA would be removed. However, during the application of the REED, $V$. criceti is in a substrate-deficient state, as any lactate present in the fermentation media would also be removed with the REED setup. The curve of the LA concentration in Fig. 6 shows that almost no lactate is transported into the $\mathrm{NaOH}$ stream during the fermentation time between 20 and $60 \mathrm{~h}$. Only at the end of the fermentation at $60 \mathrm{~h}$ when lactate accumulated in the bioreactor, LA was removed. After the complete consumption of LA by $V$. criceti at $20 \mathrm{~h}$ and the subsequent LA generation by the added glucose, no LA is removed, as all the LA is converted into PA and AA.

Comparing the results for the fermentation with and without ISPR it can be seen that the application of the REED system led to an increase in specific yield and productivity. The fermentation of glucose without ISPR reached a yield of $0.35 \mathrm{~g} \mathrm{~g}^{-1}$ with a productivity of $0.63 \mathrm{~g} \mathrm{~L}^{-1} \mathrm{~h}^{-1}$, while the REED integration resulted in a yield of $0.39 \mathrm{~g} \mathrm{~g}^{-1}$ with a productivity of $0.70 \mathrm{~g} \mathrm{~L}^{-1} \mathrm{~h}^{-1}$.

Additionally, fermentation of glucose and xylose as substrate was investigated. As it can be seen from Fig. 7, the substrate was fed in pulses. Glucose and xylose are consumed simultaneously and instantly with no initial lag phase. Furthermore, lactate is produced in parallel to glucose and xylose consumption without any delay. After each addition of the substrate mixture, glucose is consumed entirely each time, while xylose is only consumed entirely the first time and residual concentrations of xylose remain unused afterwards. Moreover, after the addition of $V$. criceti to the bioreactor at $11 \mathrm{~h}$, the LA concentration drops, and subsequently, PA and AA are generated. It can be seen from the LA concentration course that the feeding combined with the REED works in a way that after $20 \mathrm{~h}$ no LA is removed from the bioreactor and the LA concentration can be maintained close to 0 , while the PA and AA production is still ongoing.
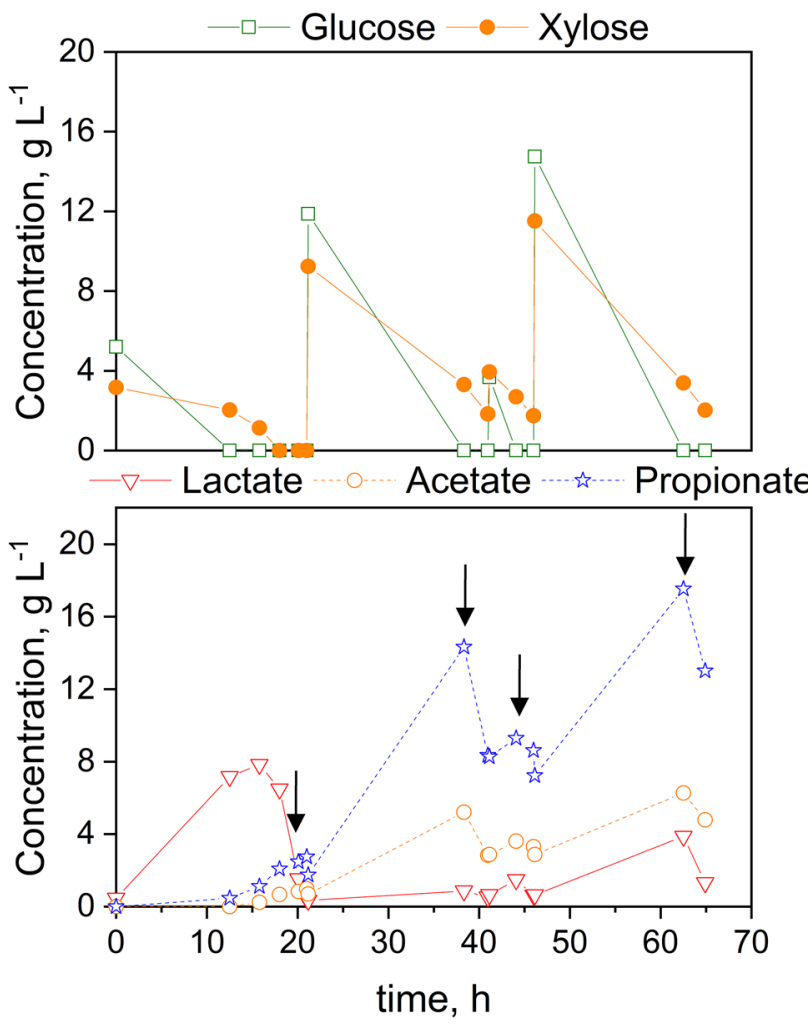

Fig. 7 Fermentation of glucose and xylose using B. coagulans and $V$. criceti. Black arrows indicate the start of an ISPR cycle (run time $2 \mathrm{~h}$ ) 
At $38 \mathrm{~h}$ and $62.5 \mathrm{~h}$, the PA concentration is reaching inhibitory levels of $14.3 \mathrm{~g} \mathrm{~L}^{-1}$ and $17.5 \mathrm{~g} \mathrm{~L}^{-1}$, respectively. As observed above, growth and PA production is still ongoing, although inhibitory levels of PA were reached. From the lower diagram of Fig. 7, it can be concluded that the removal of PA and AA was successfully performed, as both concentrations are dropping throughout the application of the REED system and the concentrations of the respective organic acids are increasing in the $\mathrm{NaOH}$ compartment, as shown in Fig. 8. In total, it was possible to remove $9.9 \mathrm{~g} \mathrm{~L}^{-1}$ of PA and $3.6 \mathrm{~g} \mathrm{~L}^{-1}$ of AA. The increase in PA in the $\mathrm{NaOH}$ stream, between 44 and $46 \mathrm{~h}$, is stemming from diffusion of these ions through the membranes due to the apparent concentration gradient, as no electrical field is applied. Combining REED and fermentation, a total amount of $23 \mathrm{~g} \mathrm{~L}^{-1}$ of PA were generated with a yield of $0.36 \mathrm{~g}$ PA per $\mathrm{g}$ substrate. Additionally, in this experiment, the highest PA production rate was reached at $0.73 \mathrm{~g} \mathrm{~L}^{-1} \mathrm{~h}^{-1}$. The residual concentrations of xylose may arise due to the fact that $B$. coagulans makes use of its preferred substrate, namely glucose and even repressing the utilization of xylose [29]. Therefore, it is possible to use a combination of sugars, such as lignocellulosic biomass for production of organic acids without the need of separation of different sugars before usage.

Relating the results of the fermentation with glucose and glucose and xylose as substrate, one can observe that the molar ratio of PA is enhanced when using mixed substrate at $2.21 \mathrm{~mol}$ PA per mol AA, while utilizing glucose at a ratio of $2.08 \mathrm{~mol}$ per mol only.

The increase in energy demand of the REED per $g$ of PA, stated in Table 1, can be explained with the improved biomass generation when using a mixed substrate in comparison to glucose as the only substrate (results not shown).

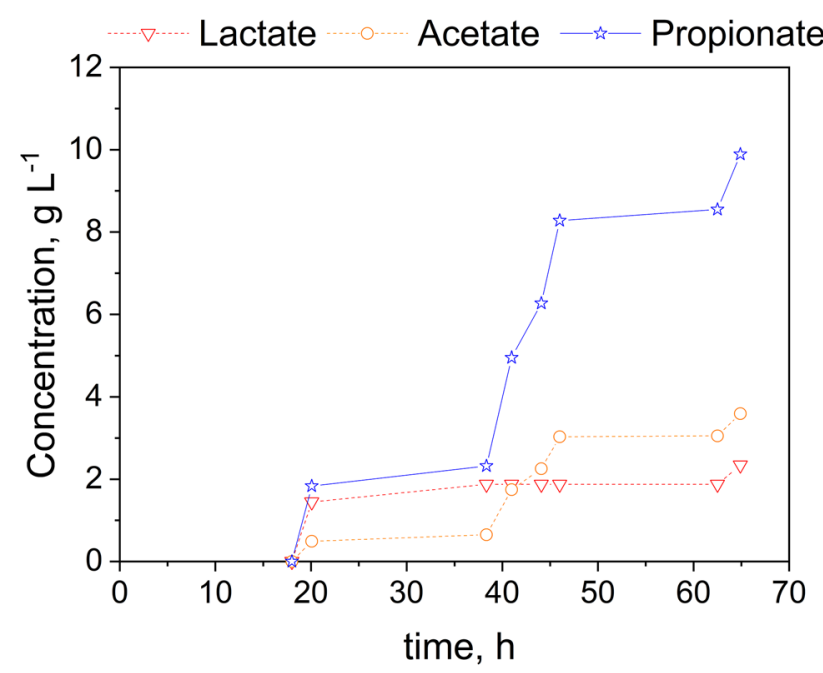

Fig. 8 Concentration of organic acids in $\mathrm{NaOH}$ compartment of REED system
Table 1 Overview of fermentation with different substrates and ISPR application

\begin{tabular}{lllll}
\hline & Substrate & $Y_{\mathrm{P} / \mathrm{S}}, \mathrm{g} \mathrm{g}^{-1}$ & $\begin{array}{l}Q_{\mathrm{P}, \max }, \\
\mathrm{g} \mathrm{L}^{-1} \\
\mathrm{~h}^{-1}\end{array}$ & $\mathrm{kWh} \mathrm{g}^{-1} \mathrm{PA}$ \\
\hline With ISPR & Glucose & 0.39 & 0.70 & $0.03 \pm 0.002$ \\
With ISPR & Glucose, xylose & 0.36 & 0.73 & $0.043 \pm 0.008$ \\
Without ISPR & Glucose & 0.35 & 0.63 & - \\
\hline
\end{tabular}

As more biomass is generated, the fouling on the membrane increases, and therefore, the resistance of the membrane stack increases, leading to higher voltages to uphold the current density. In comparison with previous studies, coculture coupled with electrodialysis has proven to enhance PA productivity, as maximum productivities reached were $0.33 \mathrm{~g} \mathrm{~L}^{-1} \mathrm{~h}^{-1}$ when using flour hydrolysate as substrate and $0.61 \mathrm{~g} \mathrm{~L}^{-1} \mathrm{~h}^{-1}$ while using glucose as a substrate in a dialysis reactor in continuous mode [10,27]. An overview of the generated experimental results can be found in Table 1 .

\section{Conclusion}

In this study, it was successfully demonstrated that a coculture of $B$. coagulans and $V$. criceti is able to produce PA from glucose and a combination of glucose and xylose via lactate. However, the product titer of propionate reached with this setup makes an industrial production not economically viable right now. An approach towards improving the product titer would be the engineering of the Veillonella strain to avoid the substrate and product inhibition. Further optimization has to be conducted regarding the feeding strategy. As the electrodialysis is also able to remove lactate, Veillonella is quickly in a substrate-deficient state during the operation of the REED. Therefore, it would be preferable to model and, in consequence, determine the optimal time point for the REED operation.

Starting from lactate as a platform intermediate gives the opportunity to establish novel processes based on lactate as the intermediate substrate when combining $B$. coagulans with a suitable partner. As B. coagulans transforms a broad variety of substrates to lactate only, it is possible to work with low-grade substrates and convert them to value-added products via a second bacterial species. Furthermore, by applying both measures, namely ISPR and co-cultures, a novel methodology towards bioprocess development can be taken. By approaching the process development according to the desired final product composition and concentration, a "process development by product design" concept is pursued. For example, for weed killing agents, a defined mixture of organic acids, such as acetic, lactic and propionic acid, is needed to ensure successful herbicidal properties [9]. 
Therefore, the bioprocess development is designed tailormade according to the desired final organic acid concentration and composition, by choosing appropriate bacterial communities, the most suitable ISPR technique, and the economically most reasonable substrate. This bottom-up strategy is especially important in the transformation of the chemical industry from a petrochemical towards a bio-based one. As up-to-date biotechnological production routes often lack the economic profitability, the same product definitions have to be reached to compete with petrochemical routes.

Acknowledgements Open Access funding provided by Projekt DEAL. We thank Anna Gorte for technical assistance.

Funding The authors acknowledge support by ERA-IB-2 (7th call) project BIOCHEM (Novel BIOrefinery platform methodology for a driven production of CHEMicals from low-grade biomass, ERA-IB-16-052), funded by the German Ministry of Education and Research (031B0270) and the project ELBE-NH: Effektivitätssteigerung von Lignin Bioraffinerien durch ergänzende Nutzung von Hydrolysaten, funded by the German Ministry of Education and Research (031B0660E).

\section{Compliance with ethical standards}

Conflict of interest The authors declare that they have no conflict of interest.

Ethical statement This article does not contain any studies with human participants or animals performed by any of the authors.

Open Access This article is licensed under a Creative Commons Attribution 4.0 International License, which permits use, sharing, adaptation, distribution and reproduction in any medium or format, as long as you give appropriate credit to the original author(s) and the source, provide a link to the Creative Commons licence, and indicate if changes were made. The images or other third party material in this article are included in the article's Creative Commons licence, unless indicated otherwise in a credit line to the material. If material is not included in the article's Creative Commons licence and your intended use is not permitted by statutory regulation or exceeds the permitted use, you will need to obtain permission directly from the copyright holder. To view a copy of this licence, visit http://creativecommons.org/licenses/by/4.0/.

\section{References}

1. Álvarez-Chávez CR, Edwards S, Moure-Eraso R, Geiser K (2012) Sustainability of bio-based plastics: general comparative analysis and recommendations for improvement. J Clean Prod 23:47-56

2. Aulitto M, Fusco S, Bartolucci S, Franzén CJ, Contursi P (2017) Bacillus coagulans MA-13: a promising thermophilic and cellulolytic strain for the production of lactic acid from lignocellulosic hydrolysate. Biotechnol Biofuels 10:210

3. Baroi GN, Skiadas IV, Westermann P, Gavala HN (2015) Effect of in situ acids removal on mixed glucose and xylose fermentation by Clostridium tyrobutyricum. AMB Express 5:67

4. Becker J, Wittmann C (2012) Bio-based production of chemicals, materials and fuels-Corynebacterium glutamicum as versatile cell factory. Curr Opin Biotechnol 23:631-640
5. Becker J, Wittmann C (2015) Advanced biotechnology: metabolically engineered cells for the bio-based production of chemicals and fuels, materials, and health-care products. Angewandte Chemie (Int ed English) 54:3328-3350

6. Bischoff KM, Liu S, Hughes SR, Rich JO (2010) Fermentation of corn fiber hydrolysate to lactic acid by the moderate thermophile Bacillus coagulans. Biotechnol Lett 32:823-828

7. Blanc P, Goma G (1987) Kinetics of inhibition in propionic acid fermentation. Bioprocess Eng 2:175-179

8. Boucher DH, James S, Keeler KH (1982) The ecology of mutualism. Annu Rev Ecol Syst 13:315-347

9. Dayan FE, Cantrell CL, Duke SO (2009) Natural products in crop protection. Bioorg Med Chem 17:4022-4034

10. Dietz D, Sabra W, Zeng A-P (2013) Co-cultivation of Lactobacillus zeae and Veillonella criceti for the production of propionic acid. AMB Express 3:29

11. Dusselier M, van Wouwe P, Dewaele A, Makshina E, Sels BF (2013) Lactic acid as a platform chemical in the bio-based economy: the role of chemocatalysis. Energy Environ Sci 6:1415

12. Feng $\mathrm{X}-\mathrm{H}$, Chen $\mathrm{F}, \mathrm{Xu} \mathrm{H}, \mathrm{Wu} \mathrm{B}$, Yao J, Ying H-J, Ouyang P-K (2010) Propionic acid fermentation by Propionibacterium freudenreichii CCTCC M207015 in a multi-point fibrous-bed bioreactor. Bioprocess Biosyst Eng 33:1077-1085

13. Fuchs G, Schlegel HG, Eitinger T (2007) Allgemeine Mikrobiologie: 53 Tabellen (8., vollst. überarb. und erw. Aufl.). Thieme, Stuttgart. https://doi.org/10.1055/b-002-44938

14. Glaser R, Venus J (2018) Co-fermentation of the main sugar types from a beechwood organosolv hydrolysate by several strains of Bacillus coagulans results in effective lactic acid production. Biotechnol Rep (Amst Neth) 18:e00245

15. Gonzalez-Garcia R, McCubbin T, Navone L, Stowers C, Nielsen L, Marcellin E (2017) Microbial propionic acid production. Fermentation 3:21

16. Huang YL, Wu Z, Zhang L, Ming Cheung C, Yang S-T (2002) Production of carboxylic acids from hydrolyzed corn meal by immobilized cell fermentation in a fibrous-bed bioreactor. Bioresour Technol 82:51-59

17. Keshav A, Chand S, Wasewar KL (2009) Recovery of propionic acid from aqueous phase by reactive extraction using quaternary amine (Aliquat 336) in various diluents. Chem Eng J 152:95-102

18. Keshav A, Wasewar KL, Chand S (2008) Extraction of propionic acid with tri-n-octyl amine in different diluents. Sep Purif Technol 63:179-183

19. Keshav A, Wasewar KL, Chand S (2009) Reactive extraction of propionic acid using tri-n-octylamine, tri-n-butyl phosphate and aliquat 336 in sunflower oil as diluent. J Chem Technol Biotechnol 84:484-489

20. Lewis VP, Yang ST (1992) A novel extractive fermentation process for propionic acid production from whey lactose. Biotechnol Prog 8:104-110

21. Lopez-Garzon CS, Straathof AJJ (2014) Recovery of carboxylic acids produced by fermentation. Biotechnol Adv 32:873-904

22. Ou MS, Ingram LO, Shanmugam KT (2011) L: (+)-Lactic acid production from non-food carbohydrates by thermotolerant Bacillus coagulans. J Ind Microbiol Biotechnol 38:599-605

23. Payot T, Chemaly Z, Fick M (1999) Lactic acid production by Bacillus coagulans - kinetic studies and optimization of culture medium for batch and continuous fermentations. Enzyme Microb Technol 24:191-199

24. Prado-Rubio OA, Jørgensen SB, Jonsson G (2011) Reverse electro-enhanced dialysis for lactate recovery from a fermentation broth. J Membr Sci 374:20-32

25. Reynolds W, Smirnova I (2018) Hydrothermal flow-through treatment of wheat straw: coupled heat and mass transfer modeling with changing bed properties. J Supercrit Fluids 133:625-639 
26. Rodriguez BA, Stowers CC, Pham V, Cox BM (2014) The production of propionic acid, propanol and propylene via sugar fermentation: an industrial perspective on the progress, technical challenges and future outlook. Green Chem 16:1066-1076

27. Sabra W, Dietz D, Zeng AP (2013) Substrate-limited co-culture for efficient production of propionic acid from flour hydrolysate. Appl Microbiol Biotechnol 97:5771-5777

28. Seeliger S, Janssen PH, Schink B (2002) Energetics and kinetics of lactate fermentation to acetate and propionate via methylmalonylCoA or acrylyl-CoA. FEMS Microbiol Lett 211:65-70

29. Stülke J, Hillen W (1999) Carbon catabolite repression in bacteria. Curr Opin Microbiol 2:195-201

30. Wang L, Xue Z, Zhao B, Yu B, Xu P, Ma Y (2013) Jerusalem artichoke powder: a useful material in producing high-optical-purity 1-lactate using an efficient sugar-utilizing thermophilic Bacillus coagulans strain. Bioresour Technol 130:174-180

31. Wang Z, Jin Y, Yang S-T (2015) High cell density propionic acid fermentation with an acid tolerant strain of Propionibacterium acidipropionici. Biotechnol Bioeng 112:502-511

32. Wang Z, Sun J, Zhang A, Yang S-T (2013) Propionic Acid Fermentation. In: Yang S-T, El-Enshasy HA, Thongchul N (eds) Bioprocessing technologies in biorefinery for sustainable production of fuels, chemicals, and polymers. Wiley, Hoboken, pp 331-350

33. Wang Z, Yang S-T (2013) Propionic acid production in glycerol/ glucose co-fermentation by Propionibacterium freudenreichii subsp. shermanii. Bioresour Technol 137:116-123
34. Yamane T, Tanaka R (2013) Highly accumulative production of $\mathrm{L}(+)$-lactate from glucose by crystallization fermentation with immobilized Rhizopus oryzae. J Biosci Bioeng 115:90-95

35. Yang H, Wang Z, Lin M, Yang S-T (2018) Propionic acid production from soy molasses by Propionibacterium acidipropionici: fermentation kinetics and economic analysis. Bioresour Technol 250:1-9

36. Zhang C, Zhou C, Assavasirijinda N, Yu B, Wang L, Ma Y (2017) Non-sterilized fermentation of high optically pure D-lactic acid by a genetically modified thermophilic Bacillus coagulans strain. Microb Cell Fact 16:213

37. Zhou X, Ye L, Wu JC (2013) Efficient production of L-lactic acid by newly isolated thermophilic Bacillus coagulans WCP10-4 with high glucose tolerance. Appl Microbiol Biotechnol 97:4309-4314

38. Zidwick MJ, Chen J-S, Rogers P (2013) Organic acid and solvent production: propionic and butyric acids and ethanol. In: Rosenberg E, DeLong EF, Lory S, Stackebrandt E, Thompson F (eds) The prokaryotes. Springer, Berlin, pp 135-167

Publisher's Note Springer Nature remains neutral with regard to jurisdictional claims in published maps and institutional affiliations. 